\title{
Urban environment connectivity and universal design solutions in Kazan (the Republic of Tatarstan, Russia)
}

\author{
Anna Akatyeva*1[0000-0002-9911-0554], \\ Dinara Nizamutdinova ${ }^{1[0000-0001-6268-686 X]}$ \\ Rinat \\ ${ }^{1}$ Kazan State University of Architecture and Engineering, 420043 Kazan, Russia
}

Hafizov $^{1[0000-0002-1601-9350]}$, and

\begin{abstract}
The article summarizes the results of the analysis of private accommodations in Kazan for people with disabilities and their families. It also presents an overview of pedagogical and project experiences in the design aspect of the universal environment in Kazan. The study includes an expert survey and case studies from the life of families. The main purpose of the study is to designate the scope of problems that prevent city integration. A key aspect in organizing an accessible and comfortable environment in the city is determined by its connectivity at the city level and implementation of universal design. The authors come to the conclusion that there are elements of universal design and accessibility in Kazan but the holistic connection and universal environment are still uncompleted. The integrity is not achieved due to the historical evolution of the city, the lack of necessary solutions at the level of transportation and pedestrian paths, urban complexes and local objects. The attitude to people with disabilities in Russian society is also considered as a factor that slows down the process of the city integration and adaptation for all.
\end{abstract}

Keywords. Urban connectivity, universal design, city, Kazan, KSUAE, people with disabilities, people with impairment, urban environment, inclusion, accessibility.

\section{Introduction}

The internal impulse for this article is associated with the personal experience of one of the authors, which arose when a child entered into the family with severe multiple developmental impairments. The author, an architect by education, was forced to take a special look at the urban environment of Kazan and on her own experience feel the degree of accessibility and inaccessibility. This personal experience was supplemented over time by conversations and interviews with other parents of special children and professionals in the field, as well as studying educational and real design. The collected information didn't always fit with official statistics, which suggests a very positive perspective in the Republic of Tatarstan and Kazan. «In 2011, the republic was the first pilot region in Russia for large-scale work on the creation of an accessible environment and the development of relevant innovative techniques» [1]. In the media, the data

*Corresponding author: akatyeva@gmail.com 
suggest that some objects in the city meet international standards and are the «best in Russia». At the same time, the opposing argument arises in the press [2].

The most significant question that was raised during this study is whether there is a connected urban environment and whether it is accessible for all people in the city. At first glance, these two aspects may seem distant, but the life experience of people with limitations in mobility makes it obvious. If we create a long pathway with one barrier, it can make the entire route inaccessible [3-6].

Humanization of society and the formation of an accessible environment - are also interrelated trends. The term «accessible environment» itself is most often used in relation to accessibility for low-mobility population: people with disabilities, older people and parents of children in wheelchairs $[3,7]$. This concept arose as an antithesis of an urban environment in which many public spaces and objects remain inaccessible to these people. Currently in practice throughout many other parts of the world the design of an accessible environment as something special, has developed beyond to universal design, or accessibility for all people [8].

In this study, we will consider these processes on the example of the city of Kazan, the capital of the Republic of Tatarstan, including problems and positive instances of the formation of a living environment, transportation network and urban facilities that are most in demand by people with limited mobility. We will also touch on a very important question of the attitude of society to people with disabilities, because it is significant for the process of humanization of society and the urban environment [9].

\section{Materials and methods}

The hypothesis of the study was that Kazan, as a holistic system, is not a universal environment accessible for people with mobility restrictions and mental disorders. Under the categories of people who are most sensitive to the accessibility of the environment, this paper considers the following: parents with young children, parents of children with disabilities, people with impaired musculoskeletal system - after injuries and operational interventions elderly people with chronic diseases, people with visual impairment, orientation in space and memory disorders. The work sets the purpose of determining those aspects that impede the formation of accessibility in the city, including spatial, cultural-historical and social.

The empirical basis of the following consists of two parts: an analysis of the urban environment and interviews with respondents. Analysis of the urban environment of Kazan on the criterion of connectivity and accessibility is made by observing, analyzing transportation maps, regular and episodic routes, urban-planning landscape complexes and architectural objects. The question of the survey part of the study is the analysis of cases of families with members with disabilities. Basically, these are children and teenagers with cerebral palsy and mental disorders, and elderly people with disabilities. Survey data was obtained by observing, conversations and detailed interviews of a small group of respondents (12 participants): people with disabilities, parents of special children and sisters of mercy. As part of the study, an interview with experts in the field of urban design, architecture and landscape design in Kazan, as well as an interview with a clinical psychologist and a palliative care physician of the Kazan hospice named after Angela Vavilova. All participants are residents of Kazan. The main issues are: positive vs negative trends of the issue under study in the city of Kazan, disconnection vs connectivity in the city, integrated environment vs elements of accessibility, attitude toward people with disabilities in the family and society as a whole.

As a part of the study, we have created interactive maps with «My maps» on the Google platform. To assess the quality of the accessibility of the environment, we suggest a verbal evaluation system and a graphical score of an available environment (Fig. 1). It is convenient for organizing a survey and graphic design of territories. For graphic image, we would like to 
use the gradation of routes and objects: green - yellow - orange - red - black. The corresponding verbal estimated characteristics of the accessibility of the environment are proposed as follows:

- impossible [black] (it is impossible to get through without special assistance);

- very difficult [red] (you can get through with great difficulties, for the first time it is incomprehensible how, but in the process, you can adapt);

- tolerant [orange] (you can get through, but there are small difficulties and obstacles);

- well [yellow] (you can get through, it is quite convenient, but the selection of the entrance is also noticeable, route for people with disabilities, the environment is not very beautiful);

- excellent [green] (everything is made as comfortable and beautiful as possible, elements and routes of the accessible environment are comprehended by the designer and integrated into the project, so it seems that it is an organic component, we no longer think about the accessible environment, the environment is universal and convenient for many/all).
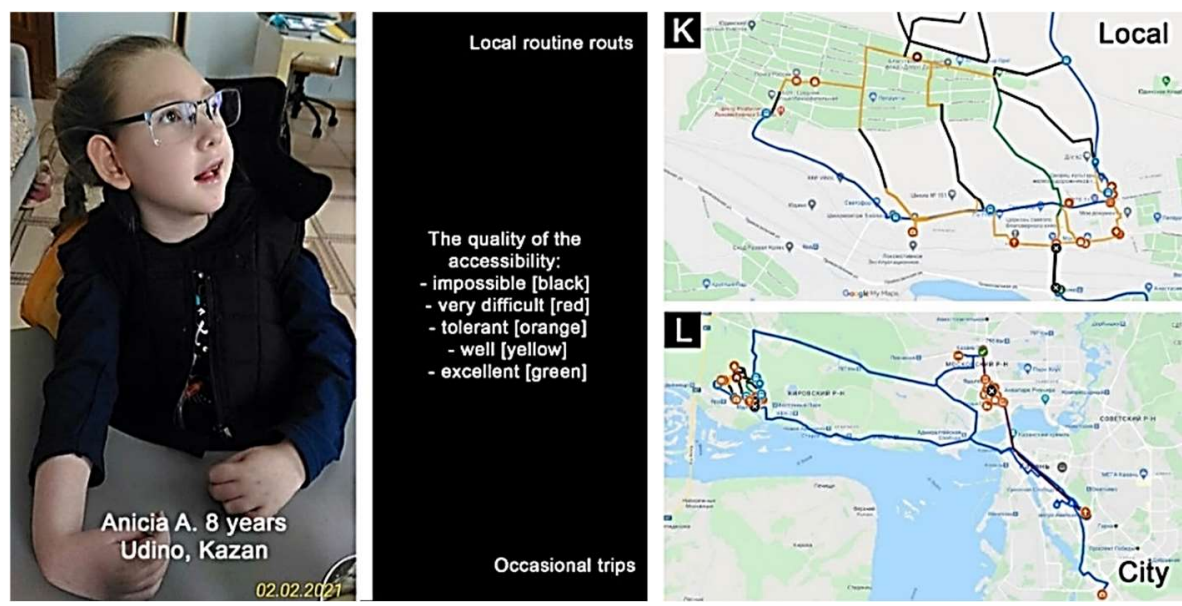

Fig. 1. The sample of the interactive accessibility maps (My maps, Google).

The study of the category of connectivity of the city made it possible to identify historical and cultural and landscape features. Kazan, as the historic city, was formed on the banks of the Volga River and developed naturally taking into account the historical influences, restrictions of the river and relief. The city has received a special growth in the twentieth century during the urbanization period. When incorporated into the structure of the city, and the industrial areas around the historic center, a middle zone was formed - a ring of industrial and warehousing enterprises, which were on the periphery (power plant, aircraft manufacturing plant, industrial port area, concrete plant). With the further growth of the city, the residential area was formed outside this ring. At the end of the twentieth century, buffer - "gray» zones were formed in connection with the decline in the intensity of industrial productivity of the city, and the urban environment has become quite loose [10-12]. According to the current plan for the development of the city of Kazan until 2050, the territory of the city will increase by 2 times due to the accession of adjacent areas, especially Zelenodolsky (microdistricts «Zalesny» and "Yudino», the residential area "Salavat Kupere», residential complexes in the worn territories in the Arakchino area). In this regard, the statement of the chief architect of Barcelona H. Asebilo, who got acquainted with the city for the first time as a part of the first project seminar «Archdesant» 2007: «Where is your city? I do not see it! I see trees here, there are trees, it is not a city». Indeed, for a person living in a tightly populated European city, our city on its periphery is rather associated with a rustic landscape. 
The question of the intensification of the urban environment and rethinking industrial zones is not new. Various contests, project seminars with international participation («Archdesant», a river port, a contest for building the territory of the gun powder plant) were devoted to it. However, the city plan for the inclusion of new territories in the city will greatly reduce the attractiveness of the renovation of industrial territories. As a result, these zones in Kazan are very poorly transformed, there are huge blind zones, which are excluded from the life in the city and increase the transportation routes and communications. This problem was well described in relation to the American experience in the book «Suburban Nation» by A. Duany and new editions dedicated to the new urbanism and the pedestrian city. These authors say that growth leads to the environmental degradation specifically as urban. This is noticeable in our city. The city will fall into pieces, pendulum migration increases, and the transportation network is very tense [13-15]. Public transportation, as an acceptable alternative to a personal car, in Kazan, unfortunately, not fully realized.

Obviously, Kazan has trends in the development of a universal environment, but they are very difficult to find in the city. Consideration of the city of Kazan as an urban environment, formed historically and maintaining an extensive growth trend, leads us to understand that a loose and interrupted environment is naturally formed in the city, often unrelated to the full structure of transportation and pedestrian routes. This understanding for us is a transition to the second key aspect which we will consider in this article - the accessibility and versatility of the urban environment.

The accessibility of the city in a broad sense belongs to the residential and public environment of the city, transportation, openness of objects for different groups of the population and goodwill to citizens. Often this term refers to the accessibility of low-mobility groups of the population, in particular, people with disabilities. However, the development of universal design shows that the environment available for this category can be convenient and attractive for all citizens. Based on the study, some aspects of accessibility at the level of urban transportation, housing, medicine, cultural, shopping and entertainment centers, religious objects and recreational areas are revealed.

\subsection{Transportation}

Comfortable movement in the city of Kazan for significant distances requires the use of transportation. In Kazan, there are various options for ground public transportation (trolley buses, buses, trams) and underground metro. Although Kazan belongs to a class of river cities and historically uses river transportation, this feature is currently missing. The renewal of a land transportation park over the last 10 years has provided the possibility of access to small groups of the population, but still, it is either difficult, or it is impossible for the following reasons: the overcrowded transportation during peak hours, short stops, lack of help from drivers or conductors, the impassibility of transition to the middle of the road boarding (for tram). The metro is partially equipped; at some stations there are special electrical lifts and personnel are very involved in helping during descent and lifting (Fig. 2e). But some stations are not equipped with lifts, and the adjacent territory does not allow easy movement. The most convenient way to move around the city is by car. This species is available for a minority of families where there are people with disabilities - often it should be a specially equipped car for walking on a carriage or a special electric chair. For many, access is the use of a special social taxi. In Kazan, such a service began to develop in the city at the expense of private initiatives. The built land transitions over highways are very difficult to traverse. A very positive solution is the transitions on demand and sidewalk equipment with ramps to the road. There is also a problem of using parking for disabled where the special parking spots are taken by other cars [16-19]. 


\subsection{Housing}

People with disabilities are very sensitive to the presence of elements of universal and special design in the residential environment. The socialization of low-mobility friendly people is dependent on this organization in many ways. The opportunity to go down to the first floor, go outside, stroll and spend time with neighbors - heavily impacts the quality of life of these people. According to the results of the study, we come to the conclusion that very often families with children with disabilities living in Kazan are forced to change the place of residence to be able to go out and access social services. The Kazan residential fund includes a fairly large number of housing units without opportunities for people with low-mobility. It is worth noting that new residential complexes, especially the categories of the business class, are built with accessibility in mind. The organization and improvement of the yard territories has improved in recent years, but so far does not have full use of a universal access.

\subsection{Regular routes}

Little private shops from the «Economy» series, pharmacies, private hairdresser and household services in Kazan often become objects with difficult accessibility. Private shops in Kazan are located in the lower floors of residential buildings along highways or streets. The peculiarity of this location is that these institutions are placed in adapted rooms with a high basement. For the organization of an accessible ramp in these institutions there is not enough space and funds. It is also worth noting there is a lack of group decisions when several institutions are located in the same building, and while you can organize a single platform for the lifting, it requires regulation and financing from the city to do it well. Now, unfortunately, this group of objects becomes an example of frequent anecdotical cases of unacceptable slopes of ramps and inconsistencies in adaptations (Fig. 2).

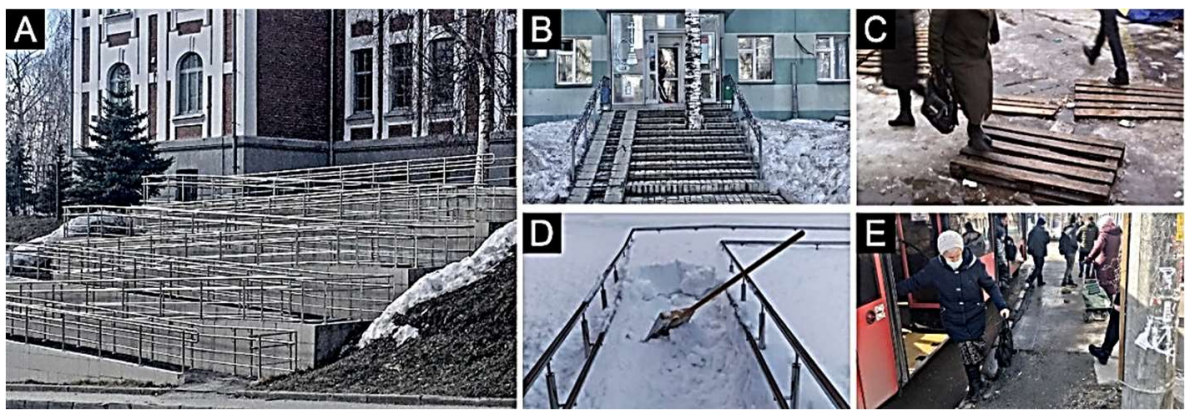

Fig. 2. The Examples of difficulties in the access in Kazan.

\subsection{Medical facilities}

Currently, many health facilities in Kazan are developing in the direction of accessibility. Such large centers like Children's Republican Clinical Hospital and Interregional clinical diagnostic center are good examples of movement in the direction of the accessible environment and universal design. Their organization in comparison with previously built and less funded facilities is certainly pleasing. However, negative occurrences are encountered quite often. For example, in the children's neurological clinic of Kazan there is no lift to the second and third floors and this makes difficult conditions for the use of the stroller. Sometimes, even the created conditions of universal design are not used in the process of real practice. For example, in the Children's Republican Clinical Hospital, the reception room has the opportunity to provide an unobstructed path through automatic swing 
doors, which is very convenient for parents with children in wheelchairs. However, the logistics of the registration is organized in such a way so that it is impossible to follow this route, and you need to enter the next double door, go through the frame and then a turnstile. In the same institution, elevators are often impossible to use because they are engaged in moving cargo and are available only by electronic key. In general, there is such a tendency that the availability of medical care for people with severe disorders is worse than for healthy children. This is due to the fact that the process of registration for hospitalization requires the collection of analysis and preliminary consultations and related expenses from various clinics, and exit services in them are poorly developed. It turns out that the more dramatic disorder a person has, the more difficult it is to get the help that is so necessary.

\subsection{Public and cultural centers}

Separate, and sometimes good solutions began to appear in this group of facilities after the introduction of mandatory accessibility for low-mobility groups. Most of the facilities of our city were built without taking into account the mandatory access of low-mobility groups, so the solution for such cultural centers is tools and assistance of the personnel. As in the survey, a child's mother with cerebral palsy answered: «I would really like to go with Luke to the theater or a concert hall, because it is interesting, and I even know that there should be some devices to assist with going, but I don't know if I could do it myself, or if would need to ask the staff to help and who I could find to organize it. How much time does it take? Can I enter the building, and get to the second floor? I do not know». In this regard, it is worth noting how important the relationships are here, the establishment of personal contact between such cultural centers and families, where there are people with disabilities.

\subsection{Educational institutions}

Secondary schools, built before the introduction of rules on an accessible environment, currently provide access to the first floor. Higher education institutions are mostly difficult to access for people with disabilities [20].

\subsection{Sports centers}

Kazan was significantly transformed in the process of preparing for the 2013 Universiade. The city has a large number of sports facilities with accessible environments, since this was required by the rules for conducting international competitions.

\subsection{Shopping and entertainment complexes}

Large shopping and entertainment complexes, built in the last decades in the city of Kazan, according to the sample of foreign analogues, are examples of a pretty accessible stay. Accessible wide openings with swing doors, elevators, universal bathrooms, lack of barriers and elevation changes when entering shops, cafes and restaurants create ease of access for moving people with shopping, mothers with wheelchairs and the disabled. Entertainment centers «Mega», «Tandem», «Park House» and «Koltso» take on the role of urban centers. The presence of facilities, entertainment, trade and related services in these centers contribute to the long-term stay of people, which is especially important in winter, when it is possible to stay on the street for a long time (links). It is these complexes that are the areas where an accessible environment is formed - accessible to the wide sections of the population and accessible to individuals with physical restrictions [21]. 


\subsection{Recreation zones}

Kazan as a comfortable pedestrian city - also remains more like a prospect. Of course, we have good promenade: Bauman Street, Peterburgskaya Street, Fedoseyevskaya Embankment, the embankment at the publishing houses, Lake Kaban embankment. However, these are separate fragments, access to which may have significant challenges. Kazan has a very active program for the improvement of courtyard territories and citywide recreation. With additional opportunities, visitors who were not able to use them before become capable. A lot of positive feedback has improved the waterfront of Lake Kaban, however, the survey shows that there are still some difficulties in overcoming the walking route. Elements of the environment here are very good, but connectivity has not yet been created. Parents with a stroller are also forced to bypass around the reconstructed Chernoe Lake Park. Similar reviews apply to the "Gorkinsko-Ometyevskiy forest" Park, where the path with the steps is not supported by an adjacent ramp for wheelchairs. Pobedy Park, Gorky Park and Uritsky Park (Fig. 3), on the contrary, have positive reviews [22].
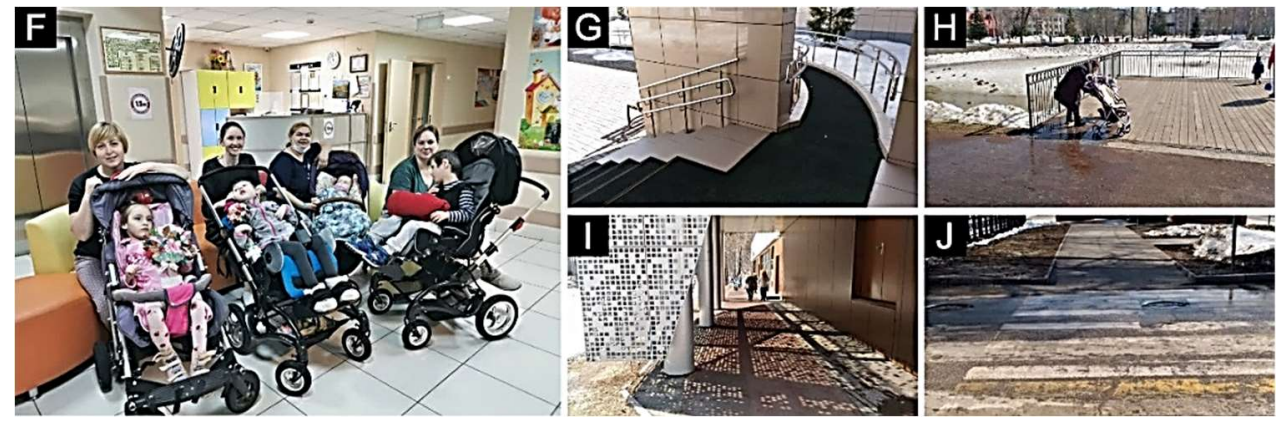

Fig. 3. Parents with their special children in the Kazan hospice and the Uritsky park nearby the hospice.

\subsection{Catering facilities}

When walking and traveling around the city, it is important for people with disabilities to take a break to sit, rest, go to the toilet and eat. In this regard, a very reliable place where there are good conditions and specially trained personnel are American fast food cafes McDonalds and KFC. The environment here is really accessible and organically organized and there is a sense of inclusion and empathy. In most restaurants, little attention is paid to the organization of an accessible environment. Often, activities relate to the facade and even a decorative nature without ensuring comfort. In the survey, it was also noted that the layout of the tables is quite dense and accommodation with a stroller causes difficulties.

\subsection{Houses of Worship}

A special group of institutions where the access of all groups of the population is important is houses of worship. When faced with difficulties caused by disabilities, people often turn to the spiritual side of their lives. Traditional religion for Tatarstan implies the participation of people in joint worship services and the life of the religious community (joint meal, training the basics of faith, the organization of mass events). Access to the temple for people with a stroller is a very difficult task, since the buildings often have a special architectural and historical value. For example, one of the most magnificent temples of Kazan - the Cathedral of Peter and Paul - is distinguished by a unique architecture, including a very high staircase to the level of the upper temple. Another illustration: in the temple of Nicholas the 
Wonderworker on Bauman Street, you enter the south side unhindered; it is often possible to see parishioners in a stroller. An interesting example of the ramp organization at the entrance is the Seraphim Sarovsky temple on Safiullina St: the ramp became an organic part of an architectural design. Due to the specifics of the architectural and planning organization of the Orthodox churches and the tradition of elevation over the level of land, the organization of accessibility is an interesting challenge for designers.

\subsection{Human factor}

Discussion of ethics of behavior in relation to people with disabilities and older people, even to their own elderly relatives is still the theme, weakly sounding in our society. Of course, there are positive trends in the form of organizing social assistance, a volunteer movement, the emergence of the first hospice in the Kazan, the construction of the second hospice, the development of the Orthodox sisterhood of mercy and the social department in the Kazan and Tatarstan diocese, the community of parents of children with the disabilities, the emergence of a social taxi for disabled people and many other improvements. Especially, I would like to note the positive effect of the pandemic, when many young people on a volunteer-basis helped the elderly and sick. However, in conversations with experts and families, we found that they are very often faced with misunderstanding, alienation, ridicule and expression of aggression in the course of life and traveling around the city. «I cried, when the children laughed at my daughter in the transport and called her disabled. I don't use public transportation anymore. We bought a car. For the same reason, we do not often go into public places. The girl also understands everything and is experiencing it too», says mother of teenage girl with cerebral palsy. Another mother says: «Often it is necessary to face misunderstanding and coldness. Only once a strange man on the street told me: Thank you for being!».

\subsection{Training and practice of designing a universal and accessible environment in Kazan}

We move to the importance of learning the design of a universal environment in the University of Architecture and Engineering and in the process of project practice. To design a high-quality universal environment, as an advanced object, it is important not only to comply with regulatory requirements, but to use a creative approach with understanding for the groups to whom the design object or complex must be accessible.

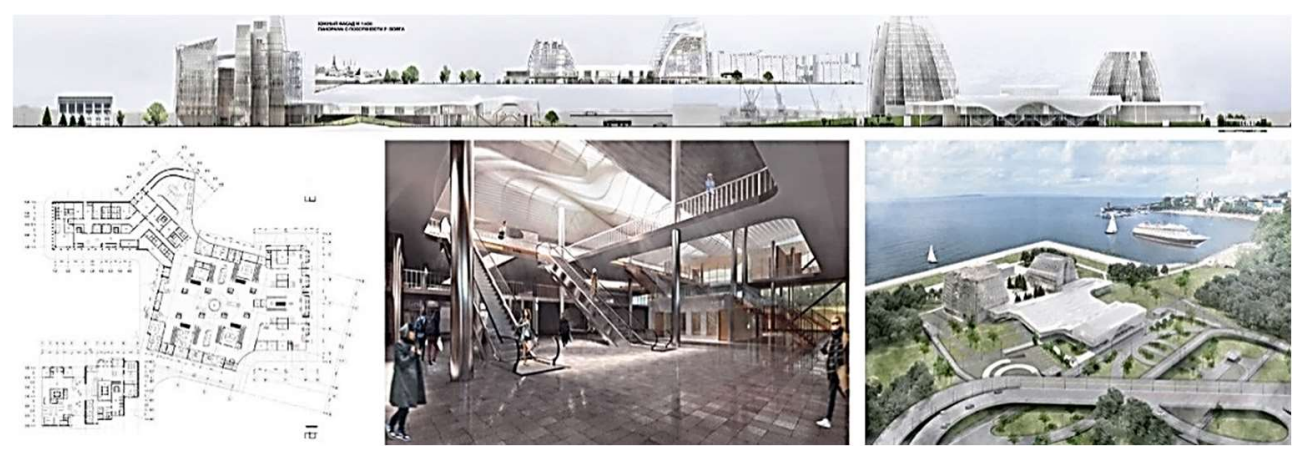

Fig. 4. The Transport hub in the River port in Kazan (bachelor diploma, KSUAE, D. Nizamutdinova).

An architect or other specialist should be familiar with groups of people with disabilities, age characteristics, a basic acquaintance with mental disorders and disorders of the 
musculoskeletal system. In the process of learning the design of a universal environment, it is important for an individual designer to have experience with people, having disabilities as a result of age or illness. It can be an experience of caring for children, elderly relatives, or as a volunteer in social projects. It is this personal experience of jointly overcoming barriers that helps to build their personal understanding in organizing the environment in training and real design (Fig. 4-5).

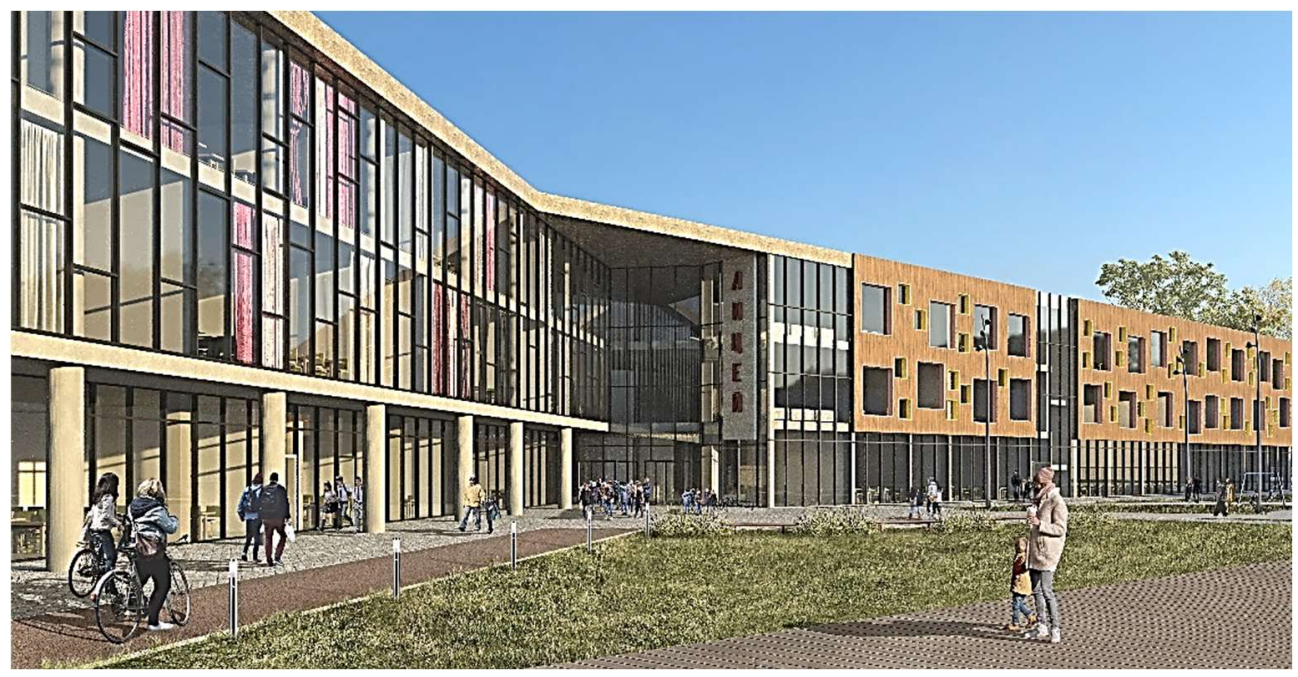

Fig. 5. The Secondary School «Krylia» (Wings) in Kazan (E. Buychurina, student project, KSUAE, 2021).

On the other hand, when designing it is very important to navigate not only for personal experience, but to take a good analogue as a basis. In this regard, it is a journey through countries and cities where the organization of a universal environment has been solved at a highly professional level. Also, familiarity with design standards and successful examples of other countries is a good help. Thus, the requirements of international standards in the field of sustainable design (LEED, DGMB, BRIAM) always motivate the designers to strive for a higher level when designing an accessible environment. For example, in the DGMB standard for office buildings, the object gets points for providing accessibility more consistently, if the access norms for the first floor are high, then the advantage will be to extend access to all floors.

Ideally, the architect must act as a lawyer for the vulnerable population. However, when architects do not feel confident in matters of an accessible environment, they will not have the power of voting. Analysis of projects and objects of the city for universality and accessibility of the environment, shows that a frequently formal solution is an extension of tribute to regulatory requirements. One important example of creating a facility with an orientation to a universal environment in Kazan is an existing hospice and another hospice hospital under construction with 60 sleeping patients. Here, from the very beginning of the design, environmental and scenario approaches were used. Now the second facility, designed with one of the author's (A. Akatyeva) participation at the «Tatinvestgrazhdanpoject», is under construction (Fig. 6).

When analyzing the design and construction process, it was also noted that at the design stages, when they are performed by different design groups, the relationship between solutions is often lost and ruptures occur. Continuity is important for the environment, but it is also important for the design and design process itself. 


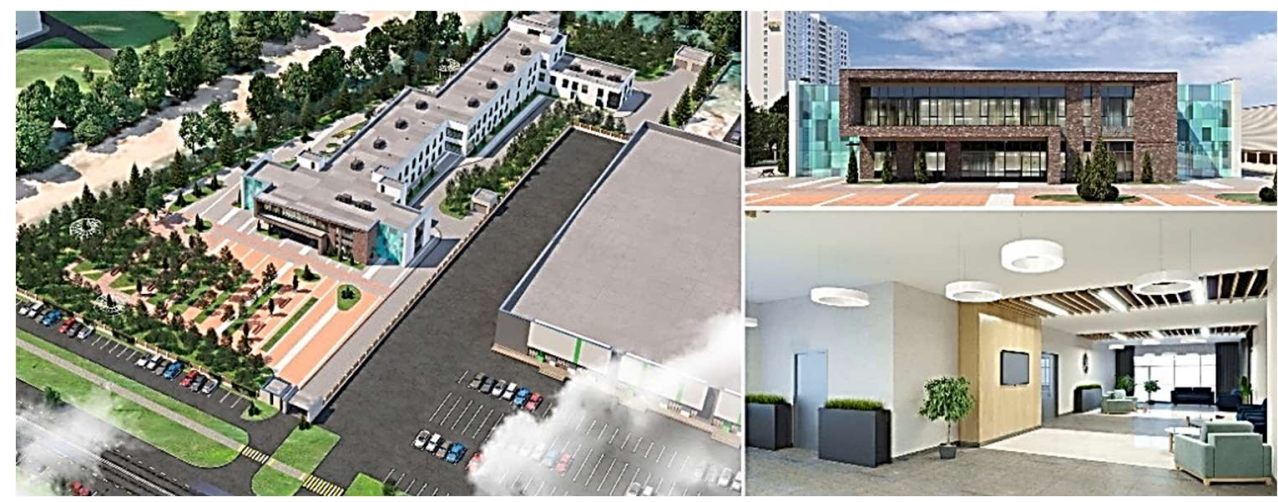

Fig. 6. The Kazan hospice designed by the «Tatinvestgrazhdanpoject» (renderings).

\section{Results}

As a result, the study has identified facts confirming the initial hypothesis and made the following conclusions:

1. A universal urban environment is formed as a unified interconnected environment of the city. In Kazan, it is possible to highlight elements and trends in the formation of this environment that are needed for integration.

2. The feature of the formation of Kazan, as a historic city, is, the urban environment has formed loosely with ruptures, buffer zones of natural and technogenic inclusions. The formation of the city as a holistic and continuous environment is complicated by this fact, and extended distances require special solutions for the transportation system.

3. The continuity and connectivity of the urban environment is one of the key factors in the formation and optimal functioning of a universal and comfort environment. The complexity of moving contributes to the isolation of the most vulnerable groups.

4. In recent decades, we can mark significant improvements in the way of forming a continuous and accessible environment. However, the number and quality of individual solutions have not yet gained such a critical mass to go into a holistic full-fledged urban environment. The formation of such an environment helps not only people with disabilities, but also all residents to live in a more accessible and positive city.

5. The emerging positive trend of the formation of an accessible environment, on the one hand, and the development of empathy and the complicity of society in the lives of people with disabilities, on the other, inspires hope for Kazan to acquire the status of a smart-city and friendly city.

6 . The architect must be a lawyer of people who are little protected and understand the high professional responsibility in the design process in matters of the quality of the environment and ethics.

\section{Discussion}

The experience of designing and implementing the principles of an accessible and universal environment has a longer history in Europe and the United States, where other attitudes towards people with limited physical and mental capabilities and, as a result, a more accessible environment. In many European and American cities, people with disabilities are fluent in the city, ride public transport or specially equipped cars, participate in public life, are not shy of their dissimilarity with normal people. Many studies are devoted to theoretical and practical issues [5$9,23,24]$. As a modern tool to reach the integration digital tools can be used effectively [25-27]. 
According to modern studies in the field of adaptation for people with special features, the most effective rehabilitation is the one that is associated with the active involvement of a person with disabilities in social life and the use of the environment. It is very important for a person with disabilities to believe that the environment takes and perceives him as a person, a person who has the right to be an active member of society to the extent that is available to him. Research in recent years in the field of rehabilitation studies focused on identifying motivation and the involvement of the environment is most promising [28, 29].

Our Russian cities are now in the twenty-first century, in particular, Kazan - the city is inaccessible to the full life of the disabled. Although the trends towards the formation of accessibility were outlined in pre-revolutionary Russia. The development of communist ideology in our country and the ideas of fascism significantly affected the development and strengthening of the tendency of polarization of society. These ideologies, singing the praises of some people, excluded others from the life of the society. Such a division has led to the lost experience of care and communicating with people having disabilities, including fears and frank squeamishness to them that shame the families. Currently, compensation for this historical delay is a relevant challenge in the process of organizing the life of communities and cities [30].

\section{Conclusion}

This local study marks the main problems and development prospects in the Kazan continuous and universal environment. We found out that difficulties are both architectural and planning related to the development of the city and socially determined. A deeper study is required to systematize the criteria for assessing the quality and accessibility of the environment, identifying the most adequate ways to solve urban problems. In the future, an analysis of the urban environment is needed to the degree of availability, the formation of routes in accordance with the proposed scale and work in their correction. It is also necessary to use social design techniques for the formation of a loyal and open attitude towards people with disabilities, and the elderly.

The authors are grateful to the participants of the survey, parents of special children, the founder of the Charitable Foundation «Angela» V. Vavilov, a clinical psychologist T. Abuladze, palliative care physician T. Akhantyeva, honored Architect of Tatarstan E. Evseev, architectural projects' manager A. Novikova, sisters of mercy of St. Nicholas, and a special child Anisya for inspiration and valuable information. Special thanks to S. Sharp for helping with the translation.

\section{References}

1. The information on the "Accessible Environment» program's implementation in the Republic of Tatarstan, https://mert.tatarstan.ru/informatsiya-po-realizatsii-programmi. htm.

2. E. Shukaeva, People are just sit at home. Why the «Accessible Environment program» doesn't work, 07.01.2021, https://www.svoboda.org/a/31021140.html.

3. M. Smith, O. Calder-Dawe, P. Carroll, N. Kayes, R. Kearns, E. Lin, K. Witten. Space and Society2, (2021). DOI: 10.1016/j.wss.2021.100028.

4. B. Giles-Corti, A. Vernez-Moudon, R. Reis, G. Turrell, A. L Dannenberg, H. Badland, S. Foster, M. Lowe, J. Sallis, M. Stevenson, N. Owen. The Lancet 388, 2912-2924 (2016). DOI: $10.1016 / \mathrm{S} 0140-6736(16) 30066-6$.

5. S. Manley 35, 137-152 (1996). DOI: 10.1016/0169-2046(96)00310-6.

6. F. Strohmeier. Transportation Research Procedia 14, 1134-1143 (2016). DOI: 10.1016/j.trpro.2016.05.184. 
7. E. Hall. Accessibility, Editor(s): Audrey Kobayashi, International Encyclopedia of Human Geography (Second Edition), Elsevier, 1-8 (2020). DOI: 10.1016/B978-0-08102295-5.10157-X.

8. A. Zając. Transportation Research Procedia 14, 1270-1276 (2016). DOI: 10.1016/j.trpro.2016.05.199.

9. P. Slater, R. McConkey, A. Smith, L. Dubois, A. Shellard. Research in Developmental Disabilities 105, (2020). DOI: 10.1016/j.ridd.2020.103754.

10. J. Yang, Procedia Engineering 180, 136-145 (2017). DOI: 10.1016/j.proeng.2017.04.173.

11. L. Bai, Ch. Xiu, X. Feng, D. Liu. Habitat International 93, (2019). DOI: 10.1016/j.habitatint.2019.102042.

12. M. Pérez, M. Laprise, Emmanuel Rey. Sustainable Cities and Society 38, 440-451 (2018). DOI: $10.1016 /$ j.scs.2017.12.038.

13. A. Duany, E. Plater-Zyberk, J. Speck. Suburban Nation: The Rise of Sprawl and the Decline of the American Dream, North Press, NY, 290 (2000).

14. M.G.H. Bell, Chapter 20 - City logistics and the urban environment, Editor(s): Corinne Mulley, John D. Nelson, Urban Form and Accessibility, Elsevier, 359-378 (2021). DOI: 10.1016/B978-0-12-819822-3.00021-3.

15. S. Milton, A. Mold, A. Tinker, Clare Herrick, Health \& Place 58, (2019). DOI: 10.1016/j.healthplace.2019.102166.

16. T. Ross, R. Buliung. Transportation Research Part A: Policy and Practice 130, 289-299 (2019). DOI: 10.1016/j.tra.2019.08.016.

17. G.R. Bivina, A. Gupta, M. Parida. Sustainable Cities and Society 55, (2020). DOI: 10.1016/j.scs.2020.102047.

18. L. Márquez, J. C. Poveda, L. A. Vega. Journal of Transport \& Health 14, (2019). DOI: 10.1016/j.jth.2019.100583.

19. M. Cerdan Chiscano. Research in Transportation Business \& Management, (2020). DOI: 10.1016/j.rtbm.2020.100596.

20. R.P. Cadena, M.O. de Andrade, L.H. Meira, A.B. Dourado. Transportation Research Procedia 48, 1861-1880 (2020). DOI: 10.1016/j.trpro.2020.08.220.

21. S. Wu, S. Lo, Cities 72, Part A, 130-140 (2018). DOI: 10.1016/j.cities.2017.08.017.

22. M. de Waal, F. Suurenbroek, I. Nio, Chapter 3 - Responsive public spaces: Five mechanisms for the design of public space in the era of networked urbanism, Editor(s): Alessandro Aurigi, Nancy Odendaal, Shaping Smart for Better Cities, Academic Press, 33-54 (2021). DOI: 10.1016/B978-0-12-818636-7.00009-3.

23. R. Castanho, A. Vulevic, J. Fernández, L. Fernández-Pozo, J. Gómez, L. Loures, Sustainable Cities and Society 32, 181-190 (2017). DOI: 10.1016/j.scs.2017.03.026.

24. M. Prescott, W.C. Miller, F. Routhier, W.B. Mortenson. Health \& Place 64, (2020). DOI: 10.1016/j.healthplace.2020.102375.

25. Z. Rashid, J. Melià-Seguí, R. Pous, E. Peig. Future Generation Computer Systems 76, 248-261 (2017). DOI: 10.1016/j.future.2016.11.030.

26. S. Paiva, P. Castro, B. Mateus, C. Pinheiro, R. Ferreira, S. Rodrigues, J. Silva, A. Curralo, Procedia Computer Science 181, 34-41 (2021). DOI: 10.1016/j.procs.2021.01.096.

27. Y. Liu, Y. Liu, J. Tang, E. Yin, D. Hu, Z. Zhou. Computers in Biology and Medicine 118, (2020). DOI: 10.1016/j.compbiomed.2020.103618.

28. I. Novak, S. McIntyre, C. Morgan, L. Campbell, L. Dark, N. Morton, E. Stumbles, S. Wilson, S. Goldsmith. A systematic review of interventions for children with cerebral palsy: state of the evidence, Developmental Medicine \& Child Neurology, (2013). DOI: $10.1111 /$ dmen. 12246.

29. Management Of Cerebral Palsy In Children: A Guide For Allied Health Professionals, Agency for clinical innovations 148, (2018).

30. J.N. Rachele, I. Wiesel, E. van Holstein, V. Feretopoulos, T. de Vries, C. Green, E. Bicknell. Cities 100, (2020). DOI: 10.1016/j.cities.2020.102650. 